INT'L. J. OF ORG. THEORY \& BEHAV., 4(3\&4), 287-306 (2001)

\title{
THE CONCEPT OF FIT IN ORGANIZATIONAL RESEARCH
}

\author{
Prescott C. Ensign \\ Richard Ivey School of Business, University of Western \\ Ontario, London, Ontario, Canada
}

\begin{abstract}
This paper focuses on the concept of fit as a topic of research. The concept of fit has been viewed as an internal consistency among key strategic decisions or the alignment between strategic choices and critical contingencies with the environment (external), organization (internal), or both (external and internal). A number of research perspectives or approaches related to fit are presented. Research design problems are discussed: definition of terms, theoretical issues, and empirical issues. Emphasis is on how key variables or dimensions of fit are defined and measured in research.

A six-celled matrix is proposed as a conceptual scheme to distinguish different perspectives of fit and to portray congruence relationships more accurately. The matrix includes three common dimensions: strategy, organization, and environment. The matrix also suggests two levels of strategy - corporate or business - and three domains of fit-external, internal, or integrated. These suggest different research perspectives for the study of fit. Examples from the literature are provided to illustrate and support this conceptual scheme. Finally, implications for management and further study are outlined.
\end{abstract}




\section{INTRODUCTION}

A common view found in the literature is that an organization's ability to accomplish its goals involves a congruence between the organization and its external environment. This congruence is the concept of fit or alignment, which has been the focus of numerous studies. The concept of fit has been viewed as an internal consistency among key strategic decisions or the alignment between strategic choices and critical contingencies in either environmental (external) or organizational (internal) contexts.

A number of research efforts have contributed to an understanding of the concept of fit. However, a useful concept is not enough. It must be anchored in sound research before it can be incorporated into a theory of organizations. Over the years the concept of fit has acquired a prominent place in conceptual thinking without the benefit of adequate theoretical and empirical investigative rigor. The focus of this paper, therefore, is on the study of fit as an observable 0phenomenon. This will be accomplished in the following sections by examining: (1) research design problems, (2) research perspectives and approaches, (3) dimensions of fit, (4) conceptualizations of fit, and (5) implications for management and further study.

\section{RESEARCH DESIGN PROBLEMS}

In examining the literature, it is evident that there are a number of problems associated with research studies related to the concept of fit. These problems center on: definitions and lack of agreement on terms used, theoretical issues, and empirical issues. Fortunately, a number of suggestions for overcoming specific research design problems can also be found in the literature.

\section{Definitions B Lack of Agreement on Terms}

An examination of the literature reveals a number of words related to this concept: fit, alignment, coalignment, match, congruence, consistency, etc. Since use of the term generally implies that there can be a lack of fit, a number of antonyms are used: misalignment, mismatch, lack of congruence, inconsistency, etc. When referring to fit, the word is sometimes used as a noun $\mathrm{B}$ as a condition or state of being. At other times the word is used as a verb B as a process or way of arriving at a condition.

In selecting the variables to be tested, problems in definition are also evident. Defining the variables means selecting appropriate elements or components 
to be tested. Since selection and definition of the variables are critical, these will be discussed under the section Dimensions of Fit.

A major source of confusion also centers on the incorrect use of the terms congruence and contingency. Some research efforts use the terms as though they are interchangeable; however, the theoretical models and empirical methods of testing each of these differ.

\section{Theoretical Issues}

Fry and Smith ${ }^{(1)}$ suggest that in order to predict phenomena correctly, organizational research must be placed in an acceptable framework of scientific inquiry. As a first priority, research efforts should focus on the task of theory building. They recommend using Dubin's ${ }^{(2)}$ framework for constructing and testing a theory. That is, in any theory, four things must be specified: (1) the units (variables/components) in the relationship being studied, (2) the laws of relationship (interaction) among the units which specify how the units are linked, (3) the boundaries within which the laws of relationship are expected to operate, and (4) the system states in which the units of the theory take on characteristic values that are deterministic and have a persistence through time. ${ }^{(3)}$

The concept of fit is based on the assumption that an organization's ability to achieve its goals is a function of the congruence between components/variables. ${ }^{(4,5)}$ Building theories of congruence, therefore, is critical to any research effort related to the concept of fit. But the development of specific hypotheses and tests for congruence have not always followed a scientific framework. A similar problem exists regarding the conceptualization of contingency effects on organizational outcomes. ${ }^{(6)}$

Fry and Smith suggest that Dubin's model is an appropriate way of understanding and testing for congruence and contingency.

Specifying congruence hypotheses means explicitly stating, a priori, the laws of relationship among units of a theory. Y Specifying contingency hypotheses means explicitly stating a priori the various system states where the integrity of the system is maintained but in a markedly different condition $\mathrm{Y}$ from what it was previously. ${ }^{(7)}$

The important distinction between congruence and contingency theories is that congruence must be tested B in fact established B before testing for contingency. Congruence is a necessary requirement for contingency, but it is not a sufficient condition for contingency.

Organizations exist in different environments with various units (elements) that must be interrelated or associated if the organization is to be effective. ${ }^{\left({ }^{8}\right)}$ There 
is both an existence of congruence among variables (state) and a need to achieve congruence among variables (process). Congruence which specifies the form of these interrelationships is necessary because the system must manage environmental and subsystem interdependencies both across and within organizational levels. Once these congruencies or relationships are established, the organization must build linkages within levels. For example, as Lawrence and Lorsch ${ }^{(9)}$ suggest, an organization must manage subunit differentiation through integration. As the organization's environment changes, e.g., entering new markets through diversification, the organizational components that must be managed may also change.

Organization research must focus on the two goals of science B the search for understanding and prediction. In the concept of fit, understanding means possessing knowledge about the relationships among components. This means the focus is on the process B how the system works. Prediction focuses on outcomes. That is, the values of the components can be identified and the condition or state of a system as a whole can be anticipated.

The search for understanding and prediction are also important in recognizing the differences between congruence research and contingency research. Congruence research is an attempt to understand laws of relationship. Contingency research attempts to predict system states.

\section{Empirical Issues}

Although issues related to theory building are a major problem in undertaking research, empirical issues are equally critical. These problems are evident in: poorly chosen propositions, incorrectly constructed hypotheses, and inappropriate selection of methods for testing. Problems are also evident in studies that state contingency or congruence relationships but use incorrect methods to arrive at such conclusions.

Critical in any research process is developing and testing hypotheses to determine whether the theoretically predicted values are achieved in the research. The choice of conceptual constructs determines the analytical methods that can be used in testing. These tests must then be appropriately selected.

As Venkatraman ${ }^{(10)}$ suggests, there has been a general lack of theoretical and empirical correspondence in research related to the concept of fit. He outlines six ways to look at fit: moderation, mediation, matching, gestalts, profile deviation, and covariation. Each of these has a different: conceptualization of fit, number of variables, analytical scheme for testing, and measure of fit. Analytical procedures depend on the perspective of fit chosen; an investigator must use appropriate methods when examining the particular concept of fit selected.(11)

In an examination of research efforts, defining the key variables in a study is a starting point. Definitions provide the parameters or the limits for the use of 
the variables in the study. It is also necessary to identify the population sampled and the type of data collected (objective, subjective, or both). Finally, it is important to determine how the key concepts or hypotheses are tested. In general, efforts that clearly state the variables, hypotheses, and methods of testing seem to provide more rigorous and meaningful results.

\section{RESEARCH PERSPECTIVES AND APPROACHES}

As already noted, the concept of fit has been studied from a variety of perspectives. A number of researchers have focused on ways to better understand and study alignment. ${ }^{(12,13)}$ One of the most complete discussions is provided by Venkatraman and Camillus. ${ }^{(14)}$ It includes a summary of the different approaches that are generally used in research efforts. Venkatraman and Camillus ${ }^{(15)}$ use a sixcelled matrix/conceptual scheme to classify the different perspectives of fit. They organize fit as content or process along one axis and according to domain (external, internal, or both) on the other axis. These dimensions are then used to categorize existing studies of fit.

Not all perspectives include the same variables. Some focus on the relationship between strategy and the external environment, others center on strategy and the internal (organizational) components, and a few look at a combination of the two. Some studies address content issues, some process issues. Venkatraman and Camillus ${ }^{(16)}$ suggest that the different perspectives reflect the formulation and implementation stages of the strategic process.

In this paper, the discussion of research efforts is divided into the three general categories of environmental domain. That is, strategy can be aligned with the variables of environment (external), organization (internal), or both (external and internal). Dimensions of fit refers to the way variables are defined in a research effort.

\section{DIMENSIONS OF FIT}

In evaluating an empirical study, it is important to know what is being measured. In research related to the concept of fit, the major variables are: strategy, environment, and organization. But it is not enough to know that the variable to be tested is, for example, environment. It is important to know more specifically what elements or components are used to define and measure the environment. This is necessary to understand how the author theoretically constructs and operationally uses the dimension of fit to be studied. These units B elements, components, or variables B are referred to as the dimensions of fit. 


\section{Strategy Defined in the Research}

In order to understand the way strategy is defined in an empirical study, it is helpful to keep in mind two general classification systems. The first describes the level of decision making (a hierarchical orientation). Strategy can be divided into two levels: corporate strategy and business unit strategy. These have also been called primary strategy and secondary strategy. Bourgeois ${ }^{(17)}$ calls the two levels domain definition strategy and domain navigation strategy. Domain definition strategy involves the choice of domain, e.g., when an organization diversifies into a particular product or market. Domain navigation strategy involves competitive decisions made within a particular product-market or task environment. Since these two occur more or less sequentially, it is appropriate to call them primary and secondary strategies. However, it is important to remember that strategy at either level is part of a total strategy making process.

Some of the early historical studies use data from major corporations. These generally focus on strategy at the corporate level. At this level, Chandler ${ }^{(18)}$ saw strategic decisions. Miles and Snow ${ }^{(19)}$ saw entrepreneurial problems. Rumelt ${ }^{(20)}$ focused on the corporate strategy of diversification. In contrast, a number of more recent studies focus on business unit strategy. The Purdue studies and research efforts using the PIMS database generally focus on the strategic business unit (SBU).

A second way of classifying strategy is to distinguish between the content of strategy and the process of strategy. Those focusing on the content of strategy attempt to specify the strategic actions to be taken to match different environmental conditions. Most early research focused on the content of strategy (decisions to be implemented). The major advantage in looking at the content is that it is more easily identified. In addition, secondary data sources (objective data) can be used almost exclusively. Those focusing on the process of strategy view alignment as a pattern of interactions, a process of arriving at the desired configuration.

\section{Environment Defined in the Research}

In the strategic management literature, Bourgeois ${ }^{(21)}$ suggests there are three general ways to define the external environment: objects or entities, attributes, and perceptions (as conveyed by internal informants). The first way (objects or entities) looks at the general environment or the task environment (customers, suppliers, competitors, regulatory groups, etc.). The second approach looks at attributes of the environment: complexity, heterogeneity, turbulence, volatility dynamics, and degree of change exhibited in those factors. The third approach is to use perceptions of the environment by internal informants. The first two can be tested using objective or subjective measurements. The third is a subjective measurement of the external environment. 


\section{Organization Defined in the Research}

A number of early studies, including Chandler ${ }^{(22)}$ and others ${ }^{(23,24)}$ attempting to test Chandler's ideas empirically, focused primarily on structure. In these studies, structure was the major organizational component investigated. Structure was usually characterized as the degree of centralization or decentralization, e.g., functional, functional with subsidiaries, divisional (product), or holding company. A more complete way to define the organization is to use the two general classifications of structure and process.

In defining the organization for any study, it is obvious that there are a large number of organizational components available for examination. Galbraith and Nathanson ${ }^{(25)}$ suggest a way of viewing the organizational components to be aligned using a five-sided model that includes: task, structure, processes (information and decision), rewards, and people. Nadler and Tushman ${ }^{(26)}$ suggest a congruence model of the organization that includes: task, individuals, organizational arrangements, and the information organization.

\section{Performance: A Measure of Alignment}

Performance has become the generally accepted measure of the efficacy of alignment. It is used to determine the degree to which an organization is able to achieve its goals. In research efforts, there are a number of problems related to the measurement of effective alignment. Obtaining an accurate assessment of performance can be difficult. A number of recent studies have used multiple measures of performance since there is no one best way of assessment. In addition, performance may not be the only goal that should be measured. The important thing to remember is that performance is an outcome and is not one of the dimensions of fit to be aligned with organizational and environmental variables.

\section{CONCEPTUALIZATIONS OF FIT}

Studies related to the concept of fit in organizational research 0focus on the relationship between strategy and one or more organizational or environmental variables. In simplest terms, the study of congruence can be described as: strategyBenvironment, strategyBorganization, or strategyBorganizationBenvironment. These are described as different conceptualizations of fit.

In the first, fit or alignment is viewed as a relationship between strategy and the external environment. The focus is on aligning strategy with conditions external to the organization. In the Venkatraman and Camillus ${ }^{(27)}$ scheme presented earlier, this was referred to as a strategy formulation perspective. 


\section{Research Perspectives of Fit}

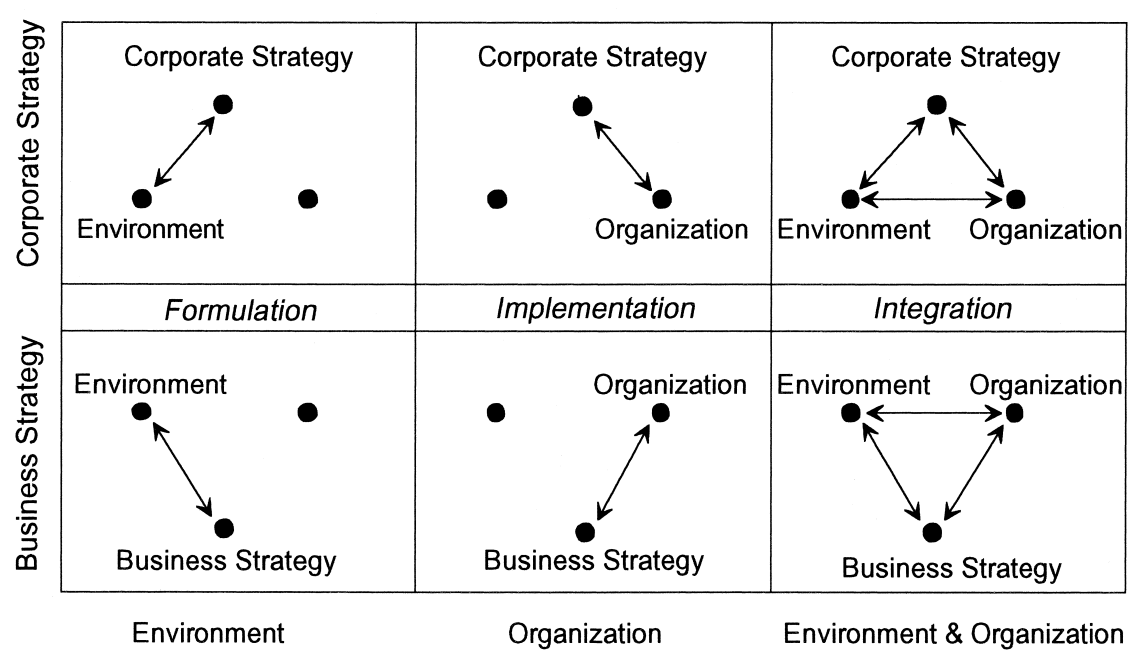

Figure 1.

In the second, fit or alignment is viewed as a relationship between strategy and organizational components (internal variables). Decisions and actions are made relative to organizational or administrative systems and strategy. This has been referred to as the strategic implementation (strategic choice) perspective. Strategic choice ${ }^{(28)}$ suggests a certain amount of managerial discretion regarding the choice of mechanisms that can be used in carrying out strategy.

In the third, fit or alignment is viewed as the relationships between strategy, organization (internal), and environment (external). This perspective emphasizes that both formulation and implementation are part of the strategic management process (an integrated approach). It may also be called an overarching or gestalt approach.

In Figure 1 strategy is used as one dimension, with the level of strategy identified as corporate strategy (primary strategy) or business strategy (secondary strategy). The other dimension includes the environmental variables B external, internal, or both (integrated).

This matrix, an attempt to portray congruence relationships more accurately, is designed to present another conceptual scheme. Figure 1 makes use of arrows to identify where and how alignment takes place. The inclusion of arrows in an alignment schema raises a major question. Is the relationship between variables (e.g., environmentBstrategy) one directional or bi-directional? Early theoretical work suggested that one variable (usually strategy) had to be aligned with one or more other variables (a reactive process). Chandler's ${ }^{(29)}$ work, for example, 
suggested that strategy determines structure. His study was followed by a number of other research efforts designed to investigate the question of direction.

Today, alignment is generally considered a proactive or interactive process. This has been demonstrated in a number of studies. Porter ${ }^{(30)}$ and Scherer ${ }^{(31)}$ found that there is a two-way interaction between market structure (external) and firm conduct (internal). Bourgeois ${ }^{(32)}$ emphasized that organizations enact their environment (proactive). As he states, an organization can define its product/market domain (primary strategy) and then manage in that chosen domain (secondary strategy).

Several studies are chosen to illustrate the type of research being conducted in each of the three domains. The examples selected also illustrate good research design. This includes: clear definitions of the major variables used (strategy, environment, and organization), clear and logical hypotheses, and appropriate methods of analysis.

\section{Strategy and Environment}

"Strategy-Making and Environment: The Third Link" (33) is an example of a study which examined the alignment between strategy and the external environment. Miller and Friesen ${ }^{(34)}$ state:

Whereas much is known about the relationships between strategy and structure, and between environment and structure, too little is known about a third link B the relationship between strategy-making and environment. An empirical study was conducted upon two distinct samples of firms. We hypothesized that increases in environmental dynamism, hostility, and heterogeneity should be related to specific changes in the amount of analysis and innovation which characterizes strategy-making activity. Most of these relationships tended to be much stronger in successful than in unsuccessful samples of firms.

Miller and Friesen provide a thorough summary of the way the dimensions of environment and strategy-making are defined, measured, and used in the study. Perceptions of the following three attributes of an environment are obtained: dynamism (uncertainty), hostility, and heterogeneity (complexity). The strategymaking process was defined by using: analysis and innovation. Three major hypotheses were designed to examine the relationship between strategy-making and the environment. Each hypothesis had two parts related to the strategy-making process: analysis and innovation.

Two databases were used to test the hypotheses. The first was a sample of 50 Canadian firms. Top level executives were tested using a questionnaire (included in the published paper). The response rate was 52 percent. A second sample of US firms was used to ensure the validity of the findings in the first 
database. This objective data had been compiled and published by Miller and Friesen in an earlier study. ${ }^{(35)}$ The data on 36 firms were divided into 135 periods. Each period was scored (using the scoring procedures and scales reported in the 1980 study) ${ }^{(36)}$ for changes in environmental dynamism, hostility, and heterogeneity as well as for changes in analysis and innovation.

The two samples were divided into two segments: high performance (firms which performed well in both sales growth and profitability) and low performance (firms which performed poorly on both sales growth and profitability). Performance was included in each hypothesis by stating: "relative to samples of poor performers, samples of successful firms will show more positive correlations between" increases in environmental dynamism and increases in (a) analysis and (b) innovation. ${ }^{(37)}$

The research findings were discussed for each of the six hypotheses. Four of the six hypotheses were supported in the study. However, as the authors suggest, the findings are tentative. Miller and Friesen also suggest that further work might isolate the causal directions in these relationships and will require more detailed longitudinal research.

A second example is a study that examined the relationship of strategy and environment by Lawless and Finch, "Choice and Determinism: A Test of Hrebiniak and Joyce's Framework on StrategyBEnvironment Fit." (38) Lawless and Finch state it has two parts: (1) to look for evidence of Hrebiniak and Joyce's environment typology in 52 manufacturing industries previously specified by Dess and Beard ${ }^{(39)}$ and (2) to test their propositions of strategyBenvironment fit by classifying 146 firms into strategic groups and then evaluating each group in each environment. ${ }^{(40)}$

Lawless and Finch ${ }^{(41)}$ use the framework developed by Hrebiniak and Joyce ${ }^{(42)}$ to investigate research questions related to: (1) the fit between an organization's strategy and environment B Are some types of strategies better suited to certain kinds of environments? and (2) the role of strategic management in shaping an organization's direction B Does strategic choice or the environment determine an organization's success?

Lawless and Finch ${ }^{(43)}$ define strategy using Miller's ${ }^{(44)}$ four business level strategies: differentiation (innovation and marketing), cost leadership (lowest cost in industry), focus (niches in an industry), and asset parsimony (reduce assets per unit of output). Environment is defined using: munificence (abundance of resources), complexity (number of linkages required to manage resources), and dynamism (change that is hard to predict). These are widely considered to be important dimensions of environment affecting organizational strategy. As Lawless and Finch $^{(45)}$ state, control over scarce resources is central to the relationship between strategic choice and environmental determinism. ${ }^{(46)}$ Resource dependencies (munificence, complexity, and dynamism) are distinct constructs affecting both choice and determinism. ${ }^{(47)}$ 
Four hypotheses were constructed using Hrebiniak and Joyce's ${ }^{(48)}$ matrix (strategic choice as one dimension with environmental determinism as the other dimension). The hypotheses focus on the four environments, each showing different strategies: minimum choice, differentiated choice, maximum choices, and incremental choice. These were related to different levels of performance. To examine the link to performance, Lawless and Finch ${ }^{(49)}$ used ten different measurements because, as they indicate, there is no single measure that is adequate or appropriate. In their study, both strategy and environment are measured using objective data. Lawless and Finch use pre-existing COMPUSTAT data for operationalizing the model to examine the environmental typology. Environmental and strategy groupings are developed using a two-step cluster analysis procedure.

\section{Strategy and Organization}

Govindarajan $^{(50)}$ conducted a study of the relationships between management procedures and strategy, "A Contingency Approach to Strategy Implementation at the Business-Unit Level: Integrating Administrative Mechanisms with Strategy." As Govindarajan ${ }^{(51)}$ states:

This study focused on what is perhaps the most critical aspect of strategy implementation in large, multi-business organizations: recognizing that different business units within the same corporation often pursue different strategies and that the administrative mechanisms that corporate headquarters use to manage those businesses should differ. This study compared the results of bivariate and systems approaches to fit. Implications of the results for theory development and managerial practice are discussed.

Govindarajan clearly recognizes the fact that most research has focused on how strategic choices are made (formulation). Limited research has focused on the design of different administrative systems that can facilitate the implementation of different business unit strategies.

Govindarajan ${ }^{(52)}$ suggests a model of strategic implementation based on the following arguments:

1. the strategy chosen by an organization determines to a large extent the uncertainty with which the organization must cope $\mathrm{Y}$

2. different administrative mechanisms are available to help organizations cope with uncertainty $\mathrm{Y}$

3. matching administrative mechanisms with strategy is likely to be associated with superior performance.

The model is based on the view that there is a strong association between strategic choice and level of environmental uncertainty. 
The three key administrative mechanisms that organizations can use to cope with uncertainty are: design of organizational structure, design of control systems, and selection of managers. ${ }^{(53)}$ The three variables used to test the model (at the business unit level) are: decentralization (structure), budget evaluative style (control), and locus of control (managerial). Since this study examines strategy at the business unit (secondary) level, strategy is viewed as the "ways in which an SBU can gain a sustainable competitive advantage over other firms in its industry." (54) Based on Porter's ${ }^{(55)}$ framework, strategy is defined as either low cost or differentiation.

The data collected in Govindarajan's ${ }^{(56)}$ study were analyzed using two different methods (bivariate and multivariate analysis). The findings from each analysis were quite different (with implications for management and further research). His study, particularly the use of multiple methods of analysis, is clearly a response to the call for more rigorous analysis of data.

An earlier study by Gupta and Govindarajan, "Business Unit Strategy, Managerial Characteristics, and Business Unit Effectiveness at Strategy Implementation," (57) also focused on strategy implementation at the business unit level. The variables selected as managerial characteristics (individual differences) are: experience (years) in marketing and sales, tolerance of ambiguity, effectiveness at strategic implementation, and willingness to take risk. The business unit mission (portfolio strategy) categories of build, hold, harvest, and divest are used. This means corporate level strategy is used and linked with a variable, in this case managerial characteristics, at the business unit level.

The measurements for effectiveness are based on: "a comparison between actual performance and a priori expectations rather than on an absolute scale." (58) They used 12 performance measures and weighted these in terms of their relative importance for the business unit. As they state, "such a multivariate approach with criterion weights was seen as particularly appropriate in a context in which, by definition, different strategic missions imply quite different sets of priorities." (59)

In general, an examination of recent literature focusing on the strategyBorganization link (implementation) reveals a limited number of studies. Overall, there are a significantly larger number of research efforts that focus on the link between strategy and environment (formulation). At present, many of the research efforts on the concept of fit in strategic management seem to take an integrated (strategyBorganizationBenvironment) approach.

\section{Strategy, Organization, and Environment}

"The Structural and Environmental Correlates of Business Strategy" (60) includes an examination of the relationships of strategy, organization structure, and environment. Miller indicates his view of structure is based on the work of Law- 
rence and Lorsch, ${ }^{(61)}$ Khandwalla, ${ }^{(62)}$ and Miller and Friesen. ${ }^{(63)}$ This view suggests that all organizations must be structured in a way that most effectively handles the contingencies in their environments. Miller uses three classes of structural (organizational) variables: uncertainty reduction, differentiation, and integration. In his opinion, different strategies will require the use of quite different structural devices (bureaucratic or organic). As a result, he classifies each of the three structural variables as bureaucratic and organic (resulting in six structural variables).

Miller ${ }^{(64)}$ uses the following broad categories to define the dimensions of strategy. These are: complex innovation (strategic differentiation using complex product innovation), marketing differentiation, breadth (scope) as well as (a) breadthBinnovation or (b) breadthBstability, and conservative cost control (efficiently producing a standard product). The result is six different strategies. The strategic and structural variables are divided using a dynamic or static time frame. The dynamic variables are tested using questionnaire data. The static variables are based on published data. Miller identifies three environmental classes: dynamism, heterogeneity, and hostility.

As Miller ${ }^{(65)}$ states, he does not believe that strategy or structure are determined by the environment but expected to find some common relationships between environmental and structural variables and those of strategy. In general, the structural and environmental classes are predicted to have a positive or negative correlation with the six different strategies. Data were collected in two stages. The first set of objective data was taken from an earlier study. ${ }^{(66)}$ The second sample was composed of 110 Canadian and Australian companies (top executives were sent a questionnaire). Justification for why each method is used in the collection of data is provided in his article.

Testing of the hypotheses was done to establish both the static and dynamic relationships between strategic, structural, and environmental variables. "It was postulated at the outset that the level of the strategic dimensions, as well as their direction of change, would have implications for the levels and directions of change respectively of structural and environmental variables." (67) Miller describes the study as exploratory and the model as tentative. Although it is an initial attempt to study all variables (an integrated approach), the results seem to indicate his effort was quite successful. It was a complete and thorough approach with meaningful findings.

A second example of an integrated approach is by Naman and Slevin, "Entrepreneurship and the Concept of Fit: A Model and Empirical Tests." (68) Naman and Slevin ${ }^{(69)}$ state:

A normative model of fit has been developed which, including the variables of entrepreneurial style, organizational structure, and mission strategy, determines a measure of the firm's fit with its environment. Y 
Data on entrepreneurial style, organization structure, mission strategy and financial performance were collected from 82 manufacturing firms. A measure of fit was calculated for each firm.

This integrated model of fit is a comprehensive model of the organization. It examines the elements to be aligned (content of fit) using subjective data. Naman and Slevin's model, examines both individual fit relationships and total fit. They use mathematically derived measurements as the basis for specifying fit. Using all data collected for all components, a measure of fit is computed. This organizational fit is then used to determine total fit with the environment.

Environmental turbulence is used to define environment. Entrepreneurial style is defined by: the willingness to take business related risks, the willingness to be proactive when competing with other firms, and the willingness to innovate. Organization structure is the extent to which organizations are structured in an organic or mechanistic way. Naman and Slevin measured mission strategy using an instrument developed by Gupta and Govindarajan ${ }^{(70)}$ that is designed to measure intended strategy. All of these are measured subjectively.

Financial performance was measured subjectively using a modified version of an instrument developed by Gupta and Govindarajan. ${ }^{(71)}$ Given the difficulties of accurately portraying performance, Naman and Slevin ${ }^{(72)}$ also relied on an objective measurement. In testing the data, multiple techniques for statistical analysis were employed. Based on their findings, Naman and Slevin conclude that an organization may need some way of balancing fit B suggesting that over-fit and under-fit are equally bad. In discussing their initial effort to mathematically model fit, they suggest limitations and weaknesses as well as areas for future study.

\section{MANAGEMENT IMPLICATIONS AND FURTHER STUDY}

In summary, it appears that the concept of fit will continue to have a central place in organizational research for the following reasons. (1) All organizations face change. (2) Context defines where an organization chooses to operate. A specific environment exists for every organization. (3) The organization has specific components that can be managed or changed within its chosen context. (4) Strategic decisions will be made related to the congruence of organizational and environmental elements in response to (and in anticipation of) changes that may occur. (5) Strategic decisions will be implemented by arranging organizational components/resources to affect this alignment or adjustment. (6) Perceptions and assessments will influence the strategic decisions formulated and implemented by management. (7) Fit is one way of describing the arrangement of all elements which impact the organization and the successful attainment of its goals. 
Research related to the concept of fit in the study of organizations will continue to be important for the following reasons. (1) No two organizations are alike. No two organizations operate in exactly the same context with the same elements and resources. (2) Individual (and corporate) decisions are based on assessments obtained through formal and informal means, use of active and passive scanning mechanisms, etc. (3) Strategic choice is involved at all stages of the decision making process. (4) Decisions and actions are made and remade because organizational and environmental factors are continually changing (dynamic state). (5) The alignment, adaptation, or arrangement of organizational components can have an impact on the successful attainment of organizational goals. (6) Some components (their number and intensity) have greater bearing on the success of this process than others. (7) Organizational research must continue to examine the relationships and interactions of all organizational elements.

However, use of the terms match, congruence, alignment, and even fit seem to suggest that the process is scientific: that there is a right and wrong (match), that things are alike (congruent), that they can be lined up in a specific order (alignment), or belong in a certain place B fit has even been compared to putting parts of a puzzle together (arrangement). My own preference would be to look at the process as dynamic organizational design. ${ }^{(73)}$ Organizational consistency could also be a better description of what takes place in the successful combination of components. Choice of strategy B especially at the formulation stage B does imply an appropriate decision based on an assessment of organizational and contextual elements. But there is no singularly right way that organization, environment, and strategy must fit together to complete the design. Unfortunately, we seem to be locked into calling it the concept of fit. But it does not really matter. Research efforts will still be looking at the same thing.

With regard to further study, the implications are clear. Research design and methods are still developing. In many cases, studies are narrowly focused and cross-sectional in nature. Although there is a place for these in studying the concept of fit, there is also a need for more broadly focused, longitudinal work B perhaps examining differences in short- and long-term fit. There exists a need for further studies on the process of strategic management, especially on how specific strategies are implemented in an organization. Studies such as "Coffin Nails and Corporate Strategies" (74) would expand our understanding of how organizations adjust to changes (even major changes) which occur and will continue to occur in our world today.

In reviewing the research, there was never a lack of suggestions regarding what could have been done or should be done. Scholars readily admit the problems and limitations in their own (and other) studies. Research efforts need to address these weaknesses. Most seem to be legitimate concerns and should be taken seriously. 


\section{ACKNOWLEDGMENTS}

The author thanks Gary Kustis and Frank Winfrey for their suggestions. This work has also benefited from comments made by participants at an Academy of Management conference where an earlier version of this paper was presented. Support as a Fulbright Scholar from the Foundation for Educational Exchange between Canada and the US, the Institute of International Education, and the J. M. Smucker Company is gratefully recognized.

\section{REFERENCES}

1. Fry, Louis W.; Smith, Deborah A. Congruence, Contingency, and Theory Building. Academy of Management Review 1987, 12 (Jan), 117B132.

2. Dubin, Robert. Theory Building; Free Press: New York, NY., 1978.

3. Fry, Louis W.; Smith, Deborah A. Congruence, Contingency, and Theory Building. Academy of Management Review 1987, 12 (Jan), 118.

4. Chorn, Norman H. The Alignment Theory: Creating Strategic Fit. Management Decision 1991, 29 (1), 20 B24.

5. Govindarajan, Vijay. Implementing Competitive Strategies at the Business Unit Level: Implications of Matching Managers to Strategies. Strategic Management Journal 1989, 10 (May/June), 251B269.

6. Drazin, Robert; Andrew H. Van de Ven. Alternative Forms of Fit in Contingency Theory. Administrative Science Quarterly 1985, 30 (Dec), 514B539.

7. Fry, Louis W.; Smith, Deborah A. Congruence, Contingency, and Theory Building. Academy of Management Review 1987, 12 (Jan), 120

8. Miles, Raymond H.; Snow, Charles C. Fit, Failure and the Hall of Fame. California Management Review 1984, 26 (Spring), 10B28.

9. Lawrence, Paul R.; Lorsch, Jay W. Organization and Environment: Managing Differentiation and Integration; Harvard University Press: Cambridge, Mass, 1967.

10. Venkatraman, N. The Concept of Fit in Strategy Research: Toward Verbal and Statistical Correspondence. Academy of Management Review 1989, 14 (July), 423B444.

11. Venkatraman, N. The Concept of Fit in Strategy Research: Toward Verbal and Statistical Correspondence. Academy of Management Review 1989, 14 (July), 423B444.

12. Powell, Thomas C. Organizational Alignment as Competitive Advantage. Strategic Management Journal 1992, 13 (Feb), 119B134.

13. Venkatraman, N. Performance Implications of Strategic Coalignment: A Methodological Perspective. Journal of Management Studies 1990, 27 (Jan), 19B41.

14. Venkatraman, N. and Camillus, John C. Exploring the Concept of AFit in 
Strategic Management. Academy of Management Review 1984, 9 (July), 513B525.

15. Venkatraman, N. and Camillus, John C. Exploring the Concept of AFit in Strategic Management. Academy of Management Review 1984, 9 (July), 513B525.

16. Venkatraman, N.; Camillus, John C. Exploring the Concept of A Fit in Strategic Management. Academy of Management Review 1984, 9 (July), 513B525.

17. Bourgeois, L. J., III. Strategy and Environment: A Conceptual Integration. Academy of Management Review 1980, 5 (Jan), 25 B39.

18. Chandler, Alfred D., Jr. Strategy and Structure: Chapters in the History of the Industrial Enterprise; MIT Press: Cambridge, Massachusetts, 1962.

19. Miles, Raymond H.; Snow, Charles C. Organizational Strategy, Structure, and Process; McGraw-Hill: New York, 1978.

20. Rumelt, Richard P. Strategy, Structure, and Economic Performance; Harvard University Press: Cambridge, Massachusetts, 1974.

21. Bourgeois, L. J., III. Strategic Goals, Perceived Uncertainty and Economic Performance in Volatile Environments. Academy of Management Journal 1985, 28 (June), 548B573.

22. Chandler, Alfred D., Jr. Strategy and Structure: Chapters in the History of the Industrial Enterprise; MIT Press: Cambridge, Massachusetts, 1962.

23. Donaldson, Lex. Strategy and Structural Adjustment to Regain Fit and Performance: In Defense of Contingency Theory. Journal of Management Studies 1987, 24 (Jan), 1B24.

24. Hamilton, R. T.; Shergill, G. S. The Relationship between Strategy-Structure Fit and Financial Performance in New Zealand: Evidence of Generality and Validity with Enhanced Controls. Journal of Management Studies 1992, 29 (Jan), 95B113.

25. Galbraith, Jay R.; Nathanson, Daniel A. Strategy Implementation: The Role of Structure and Process, West Publishing, St. Paul, 1978.

26. Nadler, David A.; Tushman, Michael L. A Congruence Model for Diagnosing Organizational Behavior. In Organizational Psychology: A Book of Readings, 3rd Ed., Kolb, David A.; Rubin, Irwin M.; McIntyre, James M., Eds.; Prentice-Hall: Englewood Cliffs, 1979, 442B458.

27. Venkatraman, N.; Camillus, John C. Exploring the Concept of AFit in Strategic Management. Academy of Management Review 1984, 9 (July), 513B525.

28. Child, John. Organizational Structure, Environment and Performance: The Role of Strategic Choice. Sociology 1972, 6 (Feb), 2 B22.

29. Chandler, Alfred D., Jr. Strategy and Structure: Chapters in the History of the Industrial Enterprise; MIT Press: Cambridge, Massachusetts, 1962.

30. Porter, Michael E. The Contributions of Industrial Organization to Strategic Management. Academy of Management Review 1981, 6 (Oct), 609B620. 
31. Scherer, Frederick M. Industrial Market Structure and Economic Performance; Rand McNally: Chicago, 1980.

32. Bourgeois, L. J., III. Strategy and Environment: A Conceptual Integration. Academy of Management Review 1980, 5 (Jan), 25 B39.

33. Miller, Danny; Friesen, Peter H. Strategy-Making and Environment: The Third Link. Strategic Management Journal 1983, 4 (July/Sep), 221B235.

34. Miller, Danny; Friesen, Peter H. Strategy-Making and Environment: The Third Link. Strategic Management Journal 1983, 4 (July/Sep), 221.

35. Miller, Danny; Friesen, Peter H. Momentum and Revolution in Organizational Adaptation. Academy of Management Journal 1980, 23 (Dec), 591 B614.

36. Miller, Danny; Friesen, Peter H. Momentum and Revolution in Organizational Adaptation. Academy of Management Journal 1980, 23 (Dec), 591B614.

37. Miller, Danny; Friesen, Peter H. Strategy-Making and Environment: The Third Link. Strategic Management Journal 1983, 4 (July/Sep), 223.

38. Lawless, Michael W.; Finch, Linda K. AChoice and Determinism: A Test of Hrebiniak and Joyce's Framework on Strategy Environment Fit. Strategic Management Journal 1989, 10 (July/Aug), 351B362.

39. Dess, Gregory G.; Beard, Donald W. ADimensions of Organizational Task Environments. Administrative Science Quarterly , 29 (Mar 1984), 52B73.

40. Lawless, Michael W.; Finch, Linda K. AChoice and Determinism: A Test of Hrebiniak and Joyce's Framework on Strategy Environment Fit. Strategic Management Journal 1989, 10 (July/Aug), 351.

41. Lawless, Michael W.; Finch, Linda K. AChoice and Determinism: A Test of Hrebiniak and Joyce's Framework on Strategy Environment Fit. Strategic Management Journal 1989, 10 (July/Aug), 351.

42. Hrebiniak, Lawrence G.; Joyce, William F. A Organizational Adaptation, Strategic Choice, and Environmental Determinism. Administrative Science Quarterly 1985, 30 (Sep), 336B349.

43. Lawless, Michael W.; Finch, Linda K. AChoice and Determinism: A Test of Hrebiniak and Joyce's Framework on Strategy Environment Fit. Strategic Management Journal 1989, 10 (July/Aug), 351.

44. Miller, Danny. Configurations of Strategy and Structure: Towards a Synthesis. Strategic Management Journal 1986, 7 (May/June), 233B249.

45. Lawless, Michael W.; Finch, Linda K. AChoice and Determinism: A Test of Hrebiniak and Joyce's Framework on Strategy Environment Fit. Strategic Management Journal 1989, 10 (July/Aug), 351.

46. Hrebiniak, Lawrence G.; Joyce, William F. A Organizational Adaptation, Strategic Choice, and Environmental Determinism. Administrative Science Quarterly 1985, 30 (Sep), 336B349. 
47. Dess, Gregory G.; Beard, Donald W. ADimensions of Organizational Task Environments. Administrative Science Quarterly, 29 (Mar 1984), 52B73.

48. Hrebiniak, Lawrence G.; Joyce, William F. A Organizational Adaptation, Strategic Choice, and Environmental Determinism. Administrative Science Quarterly 1985, 30 (Sep), 336B349.

49. Lawless, Michael W.; Finch, Linda K. AChoice and Determinism: A Test of Hrebiniak and Joyce's Framework on Strategy Environment Fit. Strategic Management Journal 1989, 10 (July/Aug), 351.

50. Govindarajan, Vijay. A Contingency Approach to Strategy Implementation at the Business-Unit Level: Integrating Administrative Mechanisms and Strategy. Academy of Management Journal 1988, 31 (Dec), 828B853.

51. Govindarajan, Vijay. A Contingency Approach to Strategy Implementation at the Business-Unit Level: Integrating Administrative Mechanisms and Strategy. Academy of Management Journal 1988, 31 (Dec), 828.

52. Govindarajan, Vijay. A Contingency Approach to Strategy Implementation at the Business-Unit Level: Integrating Administrative Mechanisms and Strategy. Academy of Management Journal 1988, 31 (Dec), 828B829.

53. For a treatment of this, see Miller, Danny. Stale in the Saddle: CEO Tenure and the Match between Organization and Environment. Management Science 1991, 37 (Jan), 34B52.

54. Miller, Danny. Stale in the Saddle: CEO Tenure and the Match between Organization and Environment. Management Science 1991, 37 (Jan), 830.

55. Porter, Michael E. Competitive Strategy: Techniques for Analyzing Industries and Competitors, Free Press, New York, 1980.

56. Govindarajan, Vijay. A Contingency Approach to Strategy Implementation at the Business-Unit Level: Integrating Administrative Mechanisms and Strategy. Academy of Management Journal 1988, 31 (Dec), 828B829.

57. Gupta, Anil K.; Govindarajan, Vijay. Business Unit Strategy, Managerial Characteristics, and Business Unit Effectiveness at Strategy Implementation. Academy of Management Journal 1984, 27 (Mar), 25B41.

58. Gupta, Anil K.; Govindarajan, Vijay. Business Unit Strategy, Managerial Characteristics, and Business Unit Effectiveness at Strategy Implementation. Academy of Management Journal 1984, 27 (Mar), 34.

59. Gupta, Anil K.; Govindarajan, Vijay. Business Unit Strategy, Managerial Characteristics, and Business Unit Effectiveness at Strategy Implementation. Academy of Management Journal 1984, 27 (Mar), 34.

60. Miller, Danny. The Structural and Environmental Correlates of Business Strategy. Strategic Management Journal 1987, 8 (Jan/Feb), 55B76.

61. Lawrence, Paul R.; Lorsch, Jay W. Organization and Environment: Managing Differentiation and Integration; Harvard University Press: Cambridge, Mass, 1967. 
62. Khandwalla, Pradip N. The Design of Organizations; Harcourt Brace Jovanovich: New York, 1977.

63. Miller, Danny and Friesen, Peter H. Structural Change and Performance: Quantum versus Piecemeal/Incremental Approaches. Academy of Management Journal 1982, 25 (Dec), 867B892.

64. Miller, Danny. The Structural and Environmental Correlates of Business Strategy. Strategic Management Journal 1987, 8 (Jan/Feb), 55B74.

65. Miller, Danny. The Structural and Environmental Correlates of Business Strategy. Strategic Management Journal 1987, 8 (Jan/Feb), 55B74.

66. Miller, Danny; Friesen, Peter H. Organizations: A Quantum View, PrenticeHall, Englewood Cliffs, 1984.

67. Miller, Danny. The Structural and Environmental Correlates of Business Strategy. Strategic Management Journal 1987, 8 (Jan/Feb), 55B74.

68. Naman, John L.; Slevin, Dennis P. Entrepreneurship and the Concept of Fit: A Model and Empirical Tests. Strategic Management Journal 1993, 14 (Feb), $137 \mathrm{~B} 153$.

69. Naman, John L.; Slevin, Dennis P. Entrepreneurship and the Concept of Fit: A Model and Empirical Tests. Strategic Management Journal 1993, 14 (Feb), 137.

70. Gupta, Anil K.; Govindarajan, Vijay. Business Unit Strategy, Managerial Characteristics, and Business Unit Effectiveness at Strategy Implementation. Academy of Management Journal 1984, 27 (Mar), 34.

71. Gupta, Anil K.; Govindarajan, Vijay. Business Unit Strategy, Managerial Characteristics, and Business Unit Effectiveness at Strategy Implementation. Academy of Management Journal 1984, 27 (Mar), 34.

72. Naman, John L.; Slevin, Dennis P. Entrepreneurship and the Concept of Fit: A Model and Empirical Tests. Strategic Management Journal 1993, 14 (Feb), 137.

73. For two firms under identical starting states the course of action to arrive at identical final positions may vary considerably. The term equifinality describes a state in which different initial conditions lead to similar effects. That is, certain results (a particular outcome) may be achieved given different starting conditions and by different means.

74. Miles, Robert H. Coffin Nails and Corporate Strategies; Prentice-Hall: Englewood Cliffs, 1982. 